\title{
Experimental application of a wireless earthquake damage monitoring system (WiAMS) using PZT transducers in reinforced concrete beams
}

\author{
C. E. Chalioris ${ }^{1}$, C. P. Providakis ${ }^{2}$, M. J. Favvata ${ }^{1}$, \\ N. A. Papadopoulos ${ }^{1}$, G. M. Angeli ${ }^{1} \&$ C. G. Karayannis ${ }^{1}$ \\ ${ }^{1}$ Department of Civil Engineering, \\ Democritus University of Thrace, Greece \\ ${ }^{2}$ School of Architectural Engineering, \\ Technical University of Crete, Greece
}

\begin{abstract}
An innovative portable wireless real time structural health monitoring system that can detect the earthquake damage and the structural integrity of reinforced concrete members in seismic-prone regions is experimentally evaluated. Damage detection is achieved by the use of piezoelectric transducers (actuators/sensors) and the implementation of an integration analytical approach based on the electromechanical impedance method. In this direction, piezoelectric lead zirconate titanate (PZT) transducers are bonded on the surface of the steel reinforcing bars of two large-scale reinforced concrete beams. Tested beams subjected to typical flexural monotonic and cyclic loadings and damage monitoring was performed at different loading levels, before and after yielding, using the developed system. Comparisons of the response signals acquired from the bonded piezoelectric patches for the healthy and the damaged states showed a clear gradation of the examined damage levels and provide cogent evidence that the monitoring system is sensitive from an early stage of the performed tests. The effectiveness of this structural health Wireless impedance or Admittance Monitoring System (WiAMS) to detect concrete cracking and steel yielding due to seismic excitations is also commented on. First results showed that the use of PZTs for detecting earthquake damages in reinforced concrete structures by
\end{abstract}


employing the electromechanical impedance approach can be considered as a highly promising non-destructive structural health monitoring method.

Keywords: reinforced concrete, piezoelectric lead zirconate titanate (PZT) transducer, electromechanical impedance (EMI), earthquake damage detection, experimental testing, portable wireless structural health monitoring system.

\section{Introduction}

The application of smart materials such as piezoelectric ceramics and especially piezoelectric lead zirconate titanate (PZT) in Structural Health Monitoring (SHM) techniques is a relatively recent and very promising development. The seismic problem in earthquake prone regions and the in-situ monitoring of existing Reinforced Concrete (RC) structures and further the assessment of their damage severity level and their structural integrity heighten the necessity of an effective, easy-to-apply, low cost and real-time SHM method [1].

The implementation of PZTs in SHM systems became more efficient with the development of Electro-Mechanical Impedance (EMI) method and its inverse Electro-Mechanical Admittance (EMA) method that uses electromechanical impedance (or admittance) spectrum signatures acquired across the electrodes of PZT transducers bonded or embedded in RC members [2, 3]. This procedure is based on the direct relation existed between the PZT impedance and the RC structural mechanical impedance which, in turn, is affected by the presence of damage. It combines the merits of the PZTs (small size, lightweight, low cost, active-sensing capability, long-term stability, high conversion efficiency, large range of linearity, fast response and easy-to-apply character) with the advantages of the EMI technique (increased sensitivity and efficiency in capturing localized damages in real-time utilizing high-frequency excitations without requirements of experienced technicians or complicated instrumentation) [3-7].

The EMI technique has been proved to be very sensitive to local damage near the PZT location. However, when the impedance of the host structure becomes excessively higher than the one of PZT sensor, the impedance measurement for health monitoring of large-scale structures becomes difficult. In general, impedance signatures for concrete members do not exhibit sharp peaks compared to the case for steel members $[8,9]$.

Applications of PZTs for the evaluation of the integrity of RC members showed promising results over other traditional non-destructive methods [1012]. Further, on-line monitoring of concrete compressive strength gain using PZTs has successfully been achieved [13-17]. PZT admittances were also utilized in finite element method analyses that have been carried out for the evaluation of yielding or corrosion damage in steel reinforcing bars [1, 18, 19], to localize cracking in concrete beams $[20,21]$ and to detect debonding damages in RC beams retrofitted with CFRP laminates [22, 23]. Debonding failure of CFRP retrofitted RC members significantly influences their overall performance and the decision of the strengthening technique of deficient $\mathrm{RC}$ members [22, 24, 25]. 
Recently, an innovative, portable, low cost and wireless damage monitoring system based on an alternative consideration of EMI concept integrating PZT transducers has been proposed [26]. It was denoted as Wireless impedance or Admittance Monitoring System (WiAMS) and applied initially to detect damage in plain concrete specimens. WiAMS found to be able to successfully correlate peak output voltage response signals to the onset of concrete damage while in the same time its performance depends on the specific characteristics of its components $[26,27]$.

In this paper the effectiveness of the developed monitoring platform named WiAMS is experimentally evaluated for the detection of earthquake damages in two large-scale RC beams subjected to flexural monotonic and cyclic loadings.

\section{Experimental program}

\subsection{The developed wireless structural health monitoring system WiAMS}

WiAMS is a wireless SHM system that estimates the impedance magnitude $|\mathrm{Z}|$ of a PZT transducer that is utilized in order to monitor in real-time the structural integrity of concrete members and structures. It offers extensive features such as remote control, high processing power, wireless data upload to SQL database, email notifications, scheduled, iterative impedance magnitude $|\mathrm{Z}|$ estimations and frequency span from $5 \mathrm{kHz}$ to $300 \mathrm{kHz}$ with $1 \mathrm{~Hz}$ resolution. WiAMS consists of the following multiple custom-made modules $[26,27]$, as it is also shown in fig. 1:

1. A single board computer (SBC) Raspberry Pi.

2. A custom board with the AD7357 ADC.

3. A custom board with the AD9837 frequency generator.

4. A custom interface board responsible for the power supply and the connection of the rest modules between them and with the Raspberry Pi.

5. The PZT driver module.

The impedance magnitude $|\mathrm{Z}|$ of the PZT is estimated by WiAMS based on the following consideration [26, 27]. First, the input sinusoidal voltage signal can be expressed as a function of time in the form:

$$
\mathrm{V}_{\mathrm{PZT}}(\mathrm{t})=\mathrm{V}_{\mathrm{p}} \sin (\omega \mathrm{t})
$$

where $V_{\text {PZT }}(t)$ is the voltage across the direction of the axis of the width of the PZT at time $t, V_{p}$ is the peak voltage of the voltage signal and $\omega$ is the radial frequency. The relationship between the radial frequency $\omega$ (in radians/second) and the frequency $\mathrm{f}(\mathrm{Hz})$ is $\omega=2 \pi \mathrm{f}$.

In a linear system the response current signal $\mathrm{I}(\mathrm{t})$ is shifted in phase $\varphi$ and has a different peak current $\mathrm{I}_{\mathrm{p}}$ :

$$
I(t)=I_{p} \sin (\omega t+\varphi)
$$

Taking into account that every PZT transducer under a pure and high frequency sinusoidal voltage signal behaves almost like a capacitive system that tends to 


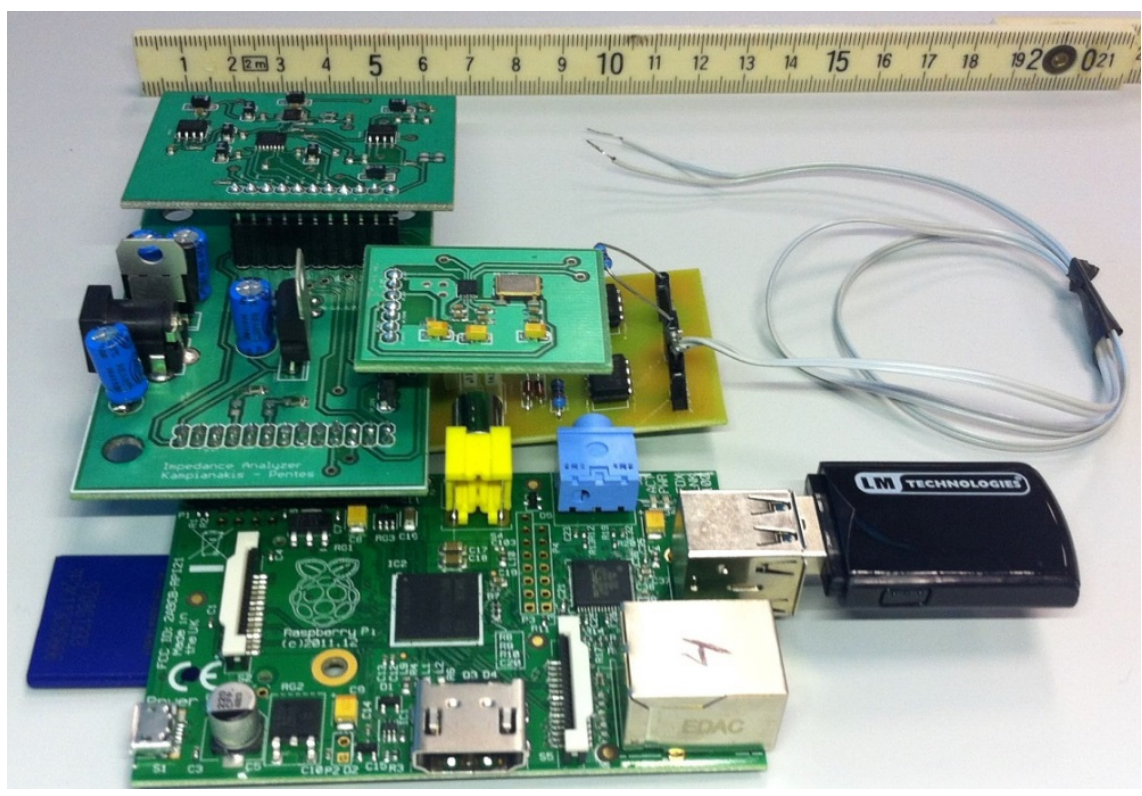

Figure 1: WiAMS modulus.

preserve the negligible phase difference between voltage and current output signal, the impedance magnitude at radial frequency $|Z(\omega)|$ can be evaluated by the expression:

$$
|Z(\omega)|=\frac{V_{p}(\omega)}{I_{p}(\omega)} \cong \frac{V_{p}(\omega)}{\frac{V_{\text {in }}(\omega)}{|Z(\omega)|+R_{f}}}
$$

where $V_{\text {in }}$ is the voltage output of the frequency generator and $R_{f}$ is a resistor connected in series with the PZT of a circuit that consists an efficient and simple method to measure impedance magnitude by exciting the device under test with a sinusoidal signal and measuring the amplitude of the voltage of the device [26].

Solving equation (3) in terms of $\mathrm{V}_{\mathrm{p}}(\omega)$, the peak value of the voltage across the PZT transducer can be estimated by:

$$
\mathrm{V}_{\mathrm{p}}(\omega) \cong \frac{|\mathrm{Z}(\omega)|}{|\mathrm{Z}(\omega)|+\mathrm{R}_{\mathrm{f}}} \mathrm{V}_{\text {in }}(\omega)
$$

Based on the above equation, it is obvious that the voltage across the PZT transducer and especially the peak voltage signal $\mathrm{V}_{\mathrm{p}}(\omega)$ provides a solid indication for the value of $|Z(\omega)|$ being directly dependent on any observed impedance amplitude variations. This way, under steady state conditions, if 
structural integrity condition of the host structure changes the peak amplitude of the voltage signal across the PZT transducer also changes. The application of expression (4) enables the implementation of simple and low-cost monitoring topologies compared to the traditional and complex impedance analysers.

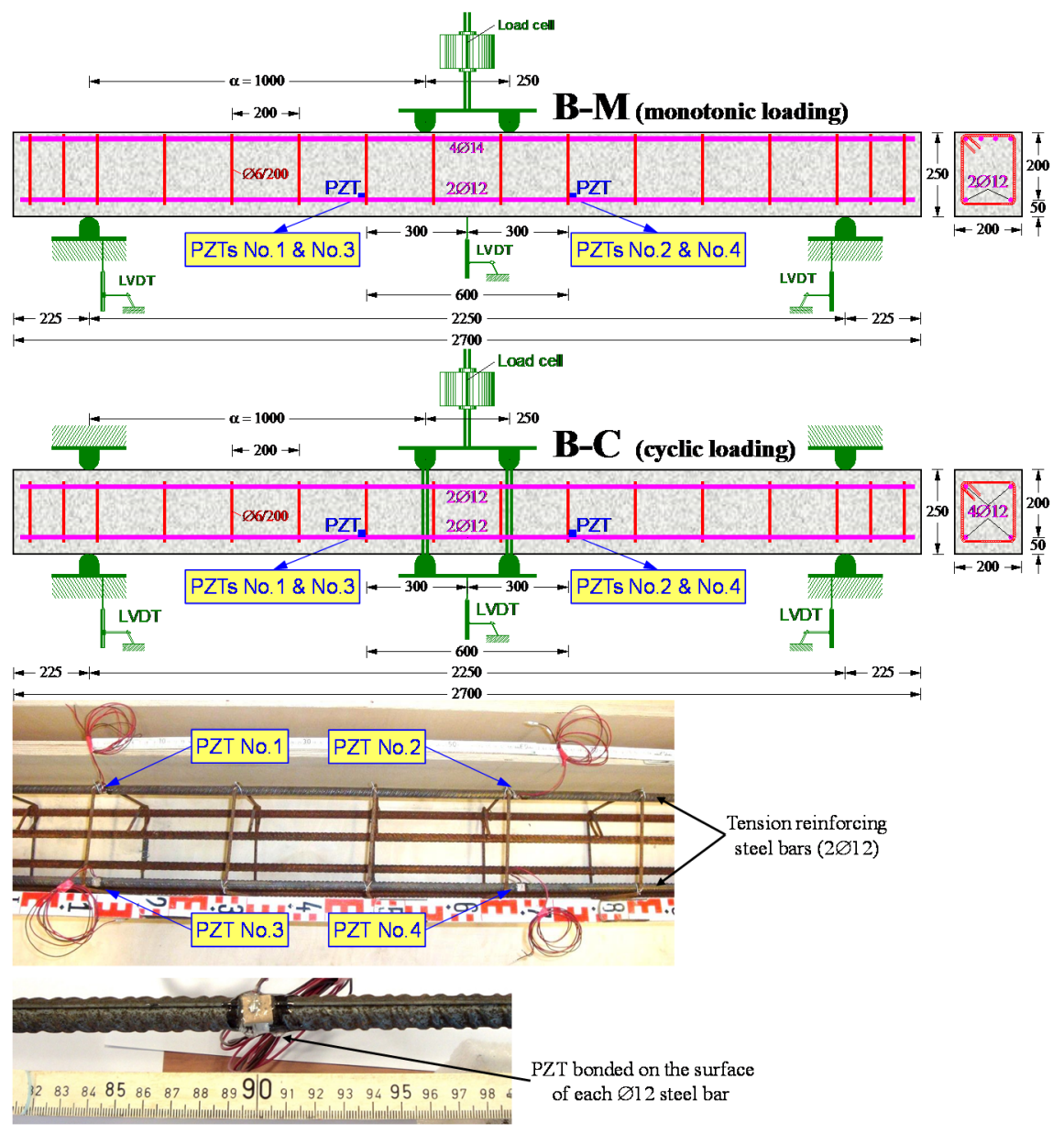

Figure 2: $\quad$ Tested RC beams.

\subsection{Test set-up and reinforced concrete beams characteristics}

The test program includes the application of the developed wireless monitoring platform to 2 large-scale RC beams under flexural monotonic loading and cyclic 
pseudo-dynamic loading. This way, the effectiveness of the developed monitoring system to evaluate the earthquake damages caused on the tensional reinforcing bars of RC beams during typical flexural tests and at different levels of loading is examined. Geometrical and reinforcement characteristics of the RC beams (B-M and B-C) are shown in fig. 2. The total length of each beam is $2.7 \mathrm{~m}$, the shear span is $1.0 \mathrm{~m}$, the height to the width ratio is $250 / 200 \mathrm{~mm}$ and the span-to-depth ratio is 5 (almost full-scale RC beams). The measured yield tensile strength of the tensional steel bars is $550 \mathrm{MPa}$ and the mean concrete cylinder compressive strength is $28.2 \mathrm{MPa}$. Two PZT patches with dimensions $10 \times 10 \mathrm{~mm}^{2}$ and material mark designation PIC 255 were bonded on the surface of each steel tensional reinforcing bar after a proper flattening of the bar of each beam (as shown in fig. 2).

A typical four-point bending scheme and setup is adopted for the flexural tests of the RC beams (fig. 2). Measurements for load and deflection were read and recorded continuously during the tests. Voltage signatures across the bonded PZTs on the steel bars of the beams were also measured using the previously described procedure with WiAMS at the beginning of each test (healthy state) and at different damage levels, before and after yielding.

\subsection{Test results}

Tested RC beams exhibited typical flexural response, as it has been designed and expected. The increase of the applied bending moment caused flexural cracks area to spread and inevitably tensional longitudinal bars to yield. Flexural moment versus mid-span deflection curves, PZT voltage versus frequency diagrams and cracking patterns of the beams B-M and B-C are presented in figs 3 and 4, respectively.

Further, the quantification of the examined damage levels of the beam B-M was carried out statistically using the well-known Root Mean Square Deviation (RMSD) index [28] as defined by:

$$
\operatorname{RMSD}=\sqrt{\frac{\sum\left(\left|\mathrm{V}_{\mathrm{p}}(\omega)\right|_{\mathrm{D}}-\left|\mathrm{V}_{\mathrm{p}}(\omega)\right|_{0}\right)^{2}}{\sum\left(\left|\mathrm{V}_{\mathrm{p}}(\omega)\right|_{0}\right)^{2}}}
$$

where $\left|V_{p}(\omega)\right|_{D}$ is the absolute value of the peak voltage of the PZT voltage signal at the examined damage state, $\left|V_{p}(\omega)\right|_{0}$ is the baseline value of the absolute value of the peak voltage of the PZT voltage signal (healthy sate) and the frequency index of each sum ranges from $10 \mathrm{kHz}$ to $250 \mathrm{kHz}$ (see also fig. 3). 

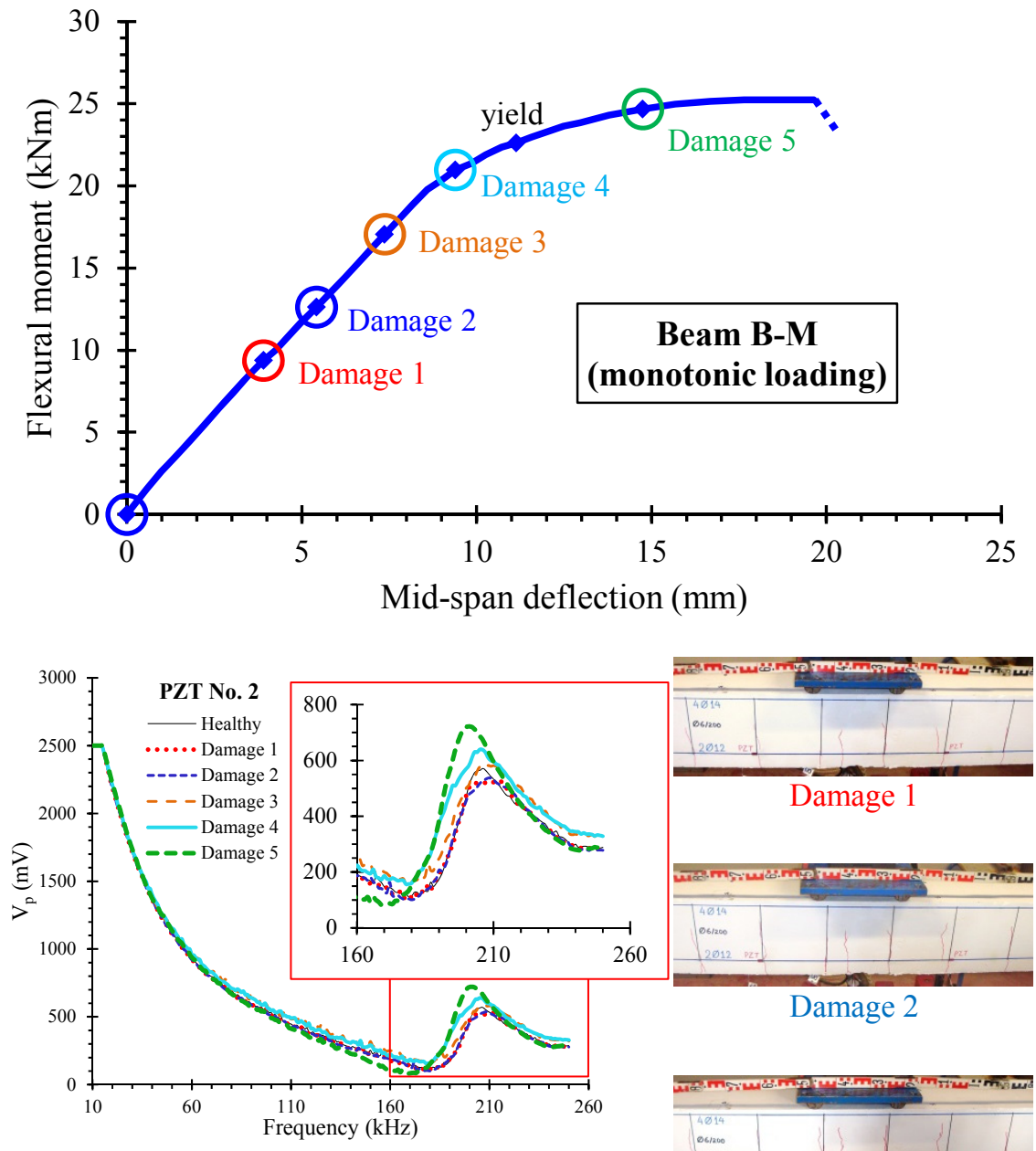

Damage 1
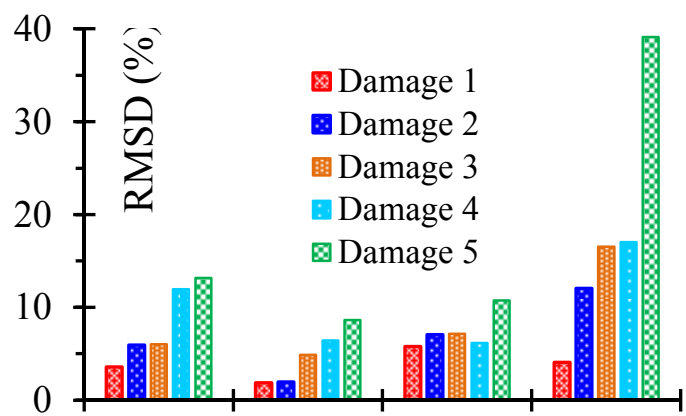

PZT PZT PZT PZT

$\begin{array}{lll}\text { No.1 No.2 No.3 No.4 } & \text { Nor }\end{array}$
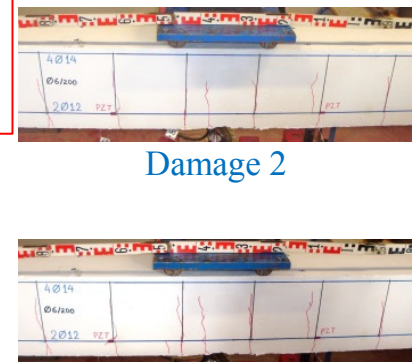

Damage 3

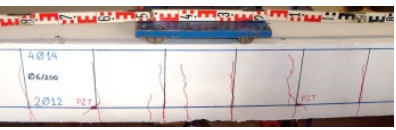

Damage 4

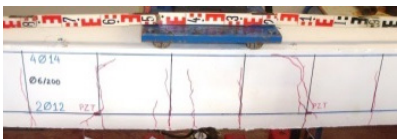

Damage 5

Figure 3: Test results of beam B-M (monotonic load). 

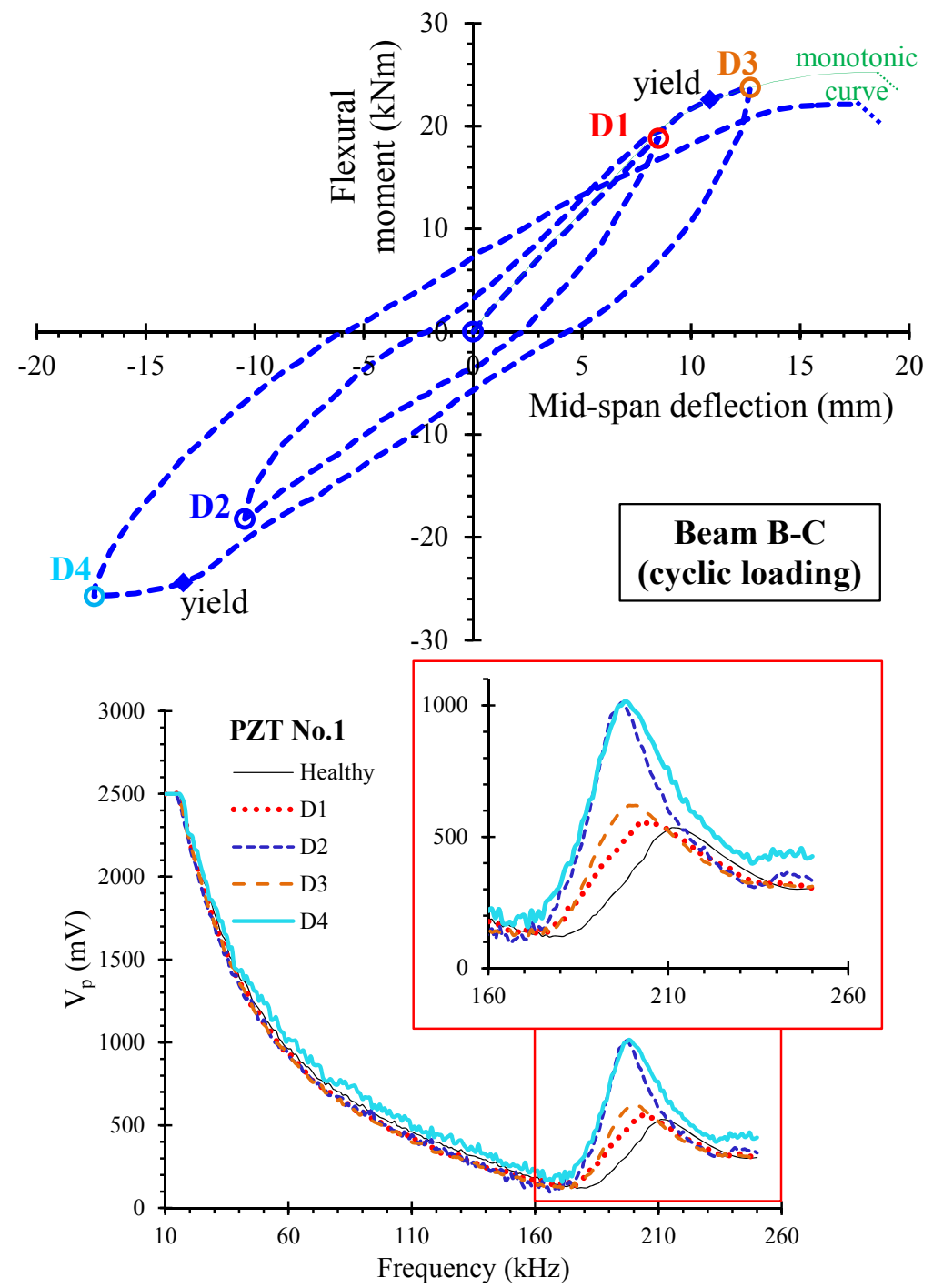

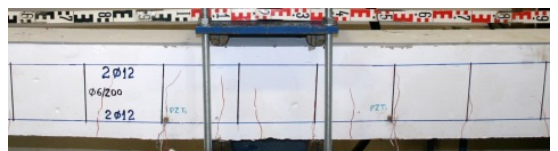

Damage 1

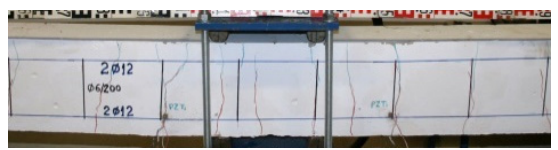

Damage 3

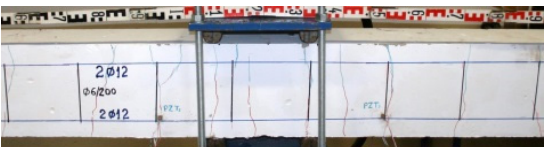

Damage 2

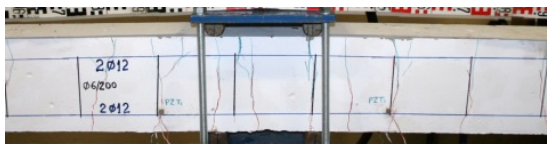

Damage 4

Figure 4: $\quad$ Tested results of beam B-C (cyclic loading). 


\section{Concluding remarks}

Voltage signatures of the bonded PZTs on the bars of the tested RC beams acquired from WiAMS measurements exhibited obvious discrepancies between the response of the healthy state of the beams and their damaged states at different load levels and for monotonic and cyclic loadings. These differences clearly indicated the presence of damage and it might be deduced that as damage level increases an increasing tendency of RMSD can be traced.

The level of the applied strain influences the material properties associated with the wave propagation properties; therefore the caused change of wave propagation properties due to strain caused by earthquake damage can be considered as the key of the efficiency of the applied technique. In this direction the present study focuses on the establishment as a link consideration to insight the main concept behind the applied technique.

\section{Acknowledgements}

This research has been co-financed by the European Union (European Social Fund-ESF) and Greek National Funds through the Operational Programme "Education and Lifelong Learning" of the National Strategic Reference Framework (NSRF) - Research Funding Program: THALES. Investing in Knowledge Society through the European Social Fund.

\section{References}

[1] Karayannis, C.G., Voutetaki, M.E., Chalioris, C.E., Providakis, C.P. \& Angeli, G.M., Detection of flexural damage stages for RC beams using piezoelectric sensors (PZT). Smart Structures and Systems, 15(4), pp. 997-1018, 2015.

[2] Song, G., Gu, H., Mo, Y.L., Hsu, T. \& Dhonde, H., Concrete structural health monitoring using embedded piezoceramic transducers, Smart Materials and Structures, 16(4), pp. 959-968, 2007.

[3] Park, G., Cudney, H.H. \& Inman D.J., Impedance-based health monitoring of civil structural components. Journal of Infrastructure Systems ASCE, 6(4), pp. 153-160, 2000.

[4] Annamdas, V.G.M. \& Soh, C.K., Application of electromechanical impedance technique for engineering structures: Review and future issues. Journal of Intelligent Materials Systems and Structures, 21(1), pp. 41-59, 2010.

[5] Shanker, R., Bhalla, S., Gupta, A. \& Kumar, M.P., Dual use of PZT patches as sensors in global dynamic and local electromechanical impedance techniques for structural health monitoring. Journal of Intelligent Materials Systems and Structures, 22(16), pp. 1841-1856, 2011. 
[6] Bhalla, S. \& Soh, C.K., Electromechanical impedance modeling for adhesively bonded piezo-transducers. Journal of Intelligent Materials Systems and Structures, 15(12), pp. 955-972, 2004.

[7] Kaur, N. \& Bhalla, S., Combined energy harvesting and structural health monitoring potential of embedded piezo-concrete vibration sensors. Journal of Energy Engineering ASCE, 10.1061/(ASCE)EY.19437897.0000224, D4014001, 2014.

[8] Kaur, N., Bhalla, S., Shanker, R. \& Panigrahi, R., Experimental evaluation of miniature impedance chip for structural health monitoring of prototype steel/ RC structures. Experimental Techniques, accepted on 20 Jan 2015, 2015.

[9] Providakis, C.P. \& Liarakos, E.V., Web based concrete strengthening monitoring using an innovative EMI telemetric system and extreme values statistics. Journal of Structural Control Health Monitoring, 21(9), pp. 1252-1268, 2014.

[10] Soh, C.K., Tseng, K.K.-H., Bhalla, S. \& Gupta. A., Performance of smart piezoceramic patches in health monitoring of a RC bridge. Smart Materials and Structures, 9(4), pp. 533-542, 2009.

[11] Yang, Y., Hu, Y. \& Lu, Y., Sensitivity of PZT impedance sensors for damage detection of concrete structures. Sensors, 8(1), pp. 327-346, 2008.

[12] Divsholi, B.S., Yang, Y. \& Bing, L., Monitoring beam-column joint in concrete structures using piezo-impedance sensors. Advanced Materials Research, 79-82, pp. 59-62, 2009.

[13] Shin, S.W. \& Oh, T.K., Application of electro-mechanical impedance sensing technique for online monitoring of strength development in concrete using smart PZT patches. Construction and Building Materials, 23(2), pp. 1185-1188, 2009.

[14] Tawie, R., Lee, H.K. \& Park, S.H., Non-destructive evaluation of concrete quality using PZT transducers. Smart Structures and Systems, 6(7), pp. 851-866, 2010.

[15] Wang, D. \& Zhu, H., Monitoring of the strength gain of concrete using embedded PZT impedance transducer. Construction and Building Materials, 25(9), pp. 3703-3708, 2011.

[16] Providakis, C.P. \& Liarakos, E.V., T-WiEYE: An early-age concrete strength development monitoring and miniaturized wireless impedance sensing system. Procedia Engineering, 10, pp. 484-489, 2011.

[17] Providakis, C.P., Liarakos, E.V. \& Kampianakis, E., Non-destructive wireless monitoring of early-age concrete strength gain using an innovative electromechanical impedance sensing system. Smart Materials Research, Article ID 932568, 10 pgs, 2013.

[18] Providakis, C.P., Angeli, G.M., Favvata, M.J., Papadopoulos, N.A., Chalioris, C.E. \& Karayannis, C.G., Detection of concrete reinforcement damage using piezoelectric materials - Analytical and experimental study. International Journal of Civil, Architectural, Structural and Construction Engineering, 8(2), pp. 197-205, 2014. 
[19] Providakis, C.P., Karayannis, C.G., Chalioris, C.E., Favvata, M.J., Angeli, G.M. \& Papadopoulos, N.A., Usage of PZTs for damage evaluation of steel reinforcing bar. Scholars Journal of Engineering and Technology, 3(1B), pp. 80-93, 2015.

[20] Providakis, C.P. \& Voutetaki, M.E., Electromechanical admittance-based damage identification using Box-Behnken design of experiments. Structural Durability and Health Monitoring, 3(4), pp. 211-227, 2007.

[21] Providakis, C.P., Stefanaki, K.D., Voutetaki, M.E., Tsompanakis, J. \& Stavroulaki, M.E., Damage detection in concrete structures using a simultaneously activated multi-mode PZT active sensing system: Numerical modelling. Structure and Infrastructure Engineering, 10(11), pp. 1451-1468, 2014.

[22] Voutetaki, M.E., Providakis, C.P. \& Chalioris, C.E., FRP debonding prevention of strengthened concrete members under dynamic load using smart piezoelectric materials (PZT). Proc. of the 15th European Conference on Composite Materials, ECCM 2012 - Composites at Venice, Venice, Italy, pp. 24-28, 2012.

[23] Providakis, C.P., Triantafillou, T.C., Karabalis, D., Papanicolaou, A., Stefanaki, K., Tsantilis, A. \& Tzoura, E., Simulation of PZT monitoring of reinforced concrete beams retrofitted with CFRP. Smart Structures and Systems, 14(5), pp. 811-830, 2014.

[24] Tsonos, A.-D.G., Effectiveness of CFRP-jackets and RC-jackets in postearthquake and pre-earthquake retrofitting of beam-column subassemblages. Engineering Structure, 30(3), pp. 777-793, 2008.

[25] Tsonos, A.-D.G., An innovative solution for strengthening of old R/C structures and for improving the FRP strengthening method. Structural Monitoring and Maintenance, 1(3), pp. 323-338, 2014.

[26] Providakis, C.P., Tsistrakis, S., Voutetaki, M.E., Tsompanakis, J., Stavroulaki, M., Agadakos, J., Kampianakis, E. \& Pentes, G., WiAMS: An innovative wireless damage detection monitoring system using electromechanical impedance-based and extreme value statistical approach. Journal of Structural Control and Health Monitoring, submitted, 2015.

[27] Providakis, C.P., Tsistrakis, S., Voutetaki, M.E., Tsompanakis, J., Stavroulaki, M., Agadakos, J., Kampianakis, E. \& Pentes, G., A wireless structural monitoring system for damage detection in concrete structures based on an electromechanical impedance-type approach. Proc. of the 6th Int. Conf. on European Bridge Conference and Exhibition, Edinburgh, Scotland, UK, 23-25 June 2015.

[28] Giurgiutiu, V., Reynolds, A. \& Rogers, C.A., Experimental investigation of E/M impedance health monitoring for spot-welded structural joints. Journal of Intelligent Materials Systems and Structures, 10(10), pp. 802812, 1999. 